ISSN 1112-9867

\title{
REDUCTION IN THE BALANCED SCORECARD PERFORMANCE MEASUREMENT SYSTEMS IN MANUFACTURING ORGANIZATIONS BY PCA
}

\author{
H. R. Massoudi ${ }^{1}$, M. Jafari-eskandari ${ }^{1}$, A. Aliahmadi ${ }^{2}$ \\ ${ }^{1}$ Department of Industrial Engineering, Payame Noor University, P.O.Box 19395.3697, Tehran, \\ Iran \\ ${ }^{2}$ Department of Industrial Engineering, Science \& Technology University, Tehran, Iran
}

Published online: 15 February 2017

\begin{abstract}
In this paper, we compare PCA and ordinal logistic regression in ranking the manufacturing systems. In this regard we present an integrated framework for assessment and ranking of manufacturing systems based on management and organizational performance indicators. To achieve the objectives of this study, a comprehensive study was conducted to locate all economic and technical indicators which influence organizational performance. Sixty one indicators were identified and classified in five categories, namely, (1) financial, (2) customer satisfaction, (3) process innovation, (4) production process and (5) organizational learning and growth. These indicators are related to organizational and managerial productivity and efficiency. One actual test problem and a random sample of 12 indicators were selected to show the applicability of the integrated approach. The results of PCA and OLR showed the weak and strong points of each sector in regard to the selected indicators. Furthermore, it identifies which indicators have the major impacts on the overall performance of industrial sectors. The modeling approach of this paper could be easily utilized for managerial and organizational ranking and analysis of other sectors. The results of such studies would help top managers to have better understanding and improve existing systems with respect to managerial and organizational performance.
\end{abstract}

Author Correspondence, e-mail: author@gmail.com

doi: http://dx.doi.org/10.4314/jfas.v9i1s.692 
Keywords: Productivity and competitiveness; Multivariate statistics integrated assessment, BCA

\section{INTRODUCTION}

Major factors influencing the overall productivity of an industrial organization are identified as technology, machinery, management, personnel and rules and procedures [1-3]. Organizational and management factors play an important role in the overall performance of manufacturing systems. In fact, managerial and organizational productivity is correlated with the overall performance of a manufacturing system. Furthermore, the overall performance of an industrial organization is often assessed by managerial and organizational productivity. The need for an integrated approach for cont inuous assessment and improvement of manufacturing systems based on management performance has become essential. *Continuous assessment requires manufacturing classifications and taxonomy to be introduced to enhance knowledge and understanding about the behavior of manufacturing systems [4-8]. Consequently, it will enable predictions to be made about organizational system behavior. In selecting a performance measure or indicator, it is important to consider the measure's suitability to the control system's objectives, the measure invasiveness and its complexity [9]. In selecting an appropriate range of performance measures it will be necessary to balance them to make sure various dimensions of manufacturing performance is considered $[10,11]$. Furthermore, we need to make sure that one or more dimensions of performance are not stressed to detriment of others.

This study has identified major productivity indicators, which affect management performance in industrial organizations. An integrated study must consider not only the traditional productivity view but also it must consider other views such as efficiency, effectiveness and profitability. Effectiveness is defined as actual output to planned output, efficiency is defined as actual output to actual input and profitability is defined as total revenue to total cost. Furthermore, this study considers the four views of management and organization productivity, which are: (1) traditional productivity, (2) efficiency, (3) effectiveness and (4) profitability. In this study, all of the four views are referred to as management and organization productivity. By consolidating a set of management and organization productivity indicators, the selected sectors may be ranked and analyzed by some Multivariate techniques such as: principal component analysis (PCA), ordinal logistic regression. Also, the validity and credibility of the PCA may be verified and validated by numerical taxonomy (NT) approach and non-parametric correlation experiments. It should be 
mentioned that data envelopment analysis (DEA) was first selected as the verification tool, but several indexes could not be considered due to the unique structure of DEA. Based on examination of 64 plants in Germany, it was concluded that machinery and training play the most important role in productivity improvement of industrial organizations [12]. Hong and colleagues showed that data envelopment analysis (DEA) can be used to evaluate the efficiency of system integration projects and proposed a methodology to overcome the limitations of DEA by utilizing DEA along with machine learning [13]. Multivariate analysis were used with the purpose of identifying critical export marketing success factors by a survey of 134 export activities of manufacturing firms in Denmark [14]. A multivariate analysis was used to test whether there is any relationship between airline flight delays and the financial situation of an airline [15].

Multivariate analysis was used to identify valuation of farmland in Spain [16]. Multivariate analysis was performed with the purpose of identifying critical export marketing success factors [17]. The relative position of United Kingdom car market was assessed with the aid of multivariate statistical analysis [18]. Other researchers used a multivariate linear statistical model to investigate the effects of speed, travel distance and part weight on robot repeatability and accuracy [19]. A fuzzy clustering and classification model for productivity analysis of machinery industry is discussed by Chen and colleagues [20]. A multivariate approach was used among 128 manufacturing organization to indicate that man-machine interfaces are significant contributors to reducing the negative effect of system complexity [21]. Three performance measures, namely, customer satisfaction, productivity and technological competitiveness were collected from a large sample of manufacturing sites in Australia and New Zealand and analyzed by multivariate analysis technique [22].Application of multivariate techniques including PCA and neural networks in a pulp mill factory is proposed and discussed by Kumar [23]. There are other studies, which show the applications of multivariate analysis in various settings [24, 25].

\section{PCA}

Principal component analysis (PCA) is widely used in multivariate statistics such as factor analysis. It is used to reduce the number of variables under study and consequently ranking and analysis of decision-making units (DMUs), such as industries, universities, hospitals, cities, etc. [26-33]. PCA was applied to selection of monitoring plants for fluoride and two indexes were found [34]. Furthermore, PCA captured the measurement correlations and reconstructed each 
variable to define associated residuals and sensor validity index. The beverage data was analyzed using PCA and cluster analysis [35]. Another study proposed several capability indices and quality measures to summarize process performance using PCA [36]. Multivariate techniques (PCA, factor analysis and cluster analysis) were applied to financial ratio data for Australian failed and non-failed companies and explained different types of information they can provide to help identify the distress levels of companies [37]. Neural networks and PCA were used for enhancement of air quality forecasting performance [38]. A process performance-monitoring scheme for a continuous process is illustrated through the application of PCA to an industrial fluidized bed reactor [39].

The objective of PCA is to identify a new set of variables such that each new variable, called a principal component, is a linear combination of original variables. Second, the first new variable y1 accounts for the maximum variance in the sample data, second new variable y2 accounts for the second maximum variance in the sample data and so on. Third, the new variables (principal components) are uncorrelated. PCA is performed by identifying Eigen structure of the covariance or singular value decomposition of the original data.

\section{Numerical taxonomy}

Numerical taxonomy approach is capable of identifying homogeneous from non-homogeneous cases. Furthermore, a group of DMUs by given indexes is divided to homogeneous sub-groups [42]. It also ranks the DMUs in a particular group.

\section{Ordinal logistic regression (K-Class logistic regression)}

Ordinal logistic regression is a less commonly used statistical modeling technique than linear regression. It is a specific modeling technique for an ordinal type of outcome. Just like the commonly used binary logistic regression, ordinal logistic regression models the log-odds of cumulative probabilities of the ordinal outcome as a linear regression function of the predictive variables. Mathematically, if a continuous outcome is classified into multiple ordered categories, ordinal logistic regression modeling could obtain unbiased beta estimates as if fitting a linear regression model to a continuous outcome. The ordinal logistic regression maintains an ordinal nature of the outcome, provides estimation of the expected probabilities for each of the ordered 
categories, and further calculates the mean score of the expected outcome, for a given set of predictive variables.

\section{Cluster analysis}

Cluster analysis is a mathematical approach used for combining observations into homogeneous clusters or groups. Each cluster is homogeneous with respect to particular characteristics. Also, each cluster is different techniques, namely: hierarchical and non-hierarchical [47-52].This study utilizes the non-hierarchical clustering approach.

\section{Integrated framework}

To achieve the objectives of this study, a comprehensive study was conducted to locate all economic and technical indicators (indexes), which influence management and organizational performance. These indicators are related to management productivity, efficiency, effectiveness and profitability. Managerial and organizational performances are categorized into four groups: financial, customers' satisfaction, internal process (including process innovation and production process) and organizational learning and growth [53-57].

Sixty-one management and organization indicators were identified as major shaping factors in manufacturing systems [58-64]. The description of all the 61 management and organization indicators is presented in Tables $1-5$. However, 12 indicators were selected randomly to simplify the purpose of our study. Standard factors such as value added, capital investment, inventory level, wages and salaries, training, research and development and production value are parameters influencing the indicators. Three indicators, namely, sales growth, salaries and wages to production value and return on investment are selected from the financial indicators (Table 1). Also, sales growth is selected from customer's satisfaction category which overlaps with the previous category (Table 2). Research and development investment to production value is selected from process innovation category (Table 3). Value of raw material inventory to production value, value of in-process inventory to production value, value of finished good inventory to production value and value of resalable defective products to production value are selected from production process indicators (Table 4). It should be noted that percent defective products is equivalent as value of resalable defective products to production value. Three of the 
12 indicators are also selected from the organizational learning and growth category that is shown in Table 5.

Table 1. Financial indicators

1. Percent sales of each product 11. Current assets turnover

2. Sales growth of each product

12. Total

assets turnover

3. Percent profitability of each product

13. Lead time of placing an order until it is received

4. Total cost of each product

Capacity utilization

5. Total revenue to total number of employees

15. Return on equity

6. Salaries and wages to production value

16. Return

on capital employed

7. Cost of raw material to production value

17. Percent net profit (from total sales)

8. Indirect costs to production value

18. Return

on assets

9. Capital investment to production value

Financial leverage

10. Return on investment

20. Return on net worth

Table 2. Customer's satisfaction indicators

1. Market share

2. Sales growth

3. Number of new customers to total number of customers in a period

4. Sales value of new customer to total sale value in a period

5. Net income to total sales value for each group of customers 
6. Number of new customers who are recommended by old customers to total number of customers in a period

7. Customer service level

8. Lead time of customers placing an after sales request

9. Cost of after sales services to total sales

10. Cost of considering environmental principals to total sales

Table 3. Process innovation indicators

1. Yield

2. Cycle time

3. Share of new products in total sales

4. Research and development investment to total sales value

5. Share of patented products to total sales

6. Supply of new products in comparison to competitors and plans

7. Required time for introduction of new generation of products

8. Measure of technological innovation in the product, i.e., how different is the technological innovation of new product in comparison to Previous product

9. Percent of products in which the original product design conforms to customer specification

10. Number of times the original product design must be modified to enter the market

11. Break even time

Table 4. Production process indicators

1. Production cycle time

2. Order cycle time

3. Manufacturing cycle efficiency

4. Yield

5. Percent defective products

6. Percent scraps

7. Percent rework

8. Percent returned products

9. Percent of process under statistical control 
10. Value of raw material inventory to production value

11. Value of in-process inventory to production value

12. Value of finished good inventory to production value

13. Actual production to planned production

Table 5. Organizational learning and growth indicators

1. Number of eligible workforce to number of required eligible workforce in each key work group

2. Production value per employee

3. Value added per employee

4. Number of employees suggestions to total number of employees

5. Number of executed suggestions to total number of suggestions

6. Number of key workforces who left the organization to total number of workforces

7. Education and training investment per employee

Table 6. The selected management and organization indicators

a1: Return on investment (ROI)

a2: Value added per employee

a3: Production value per employee

a4: Production growth (from previous year to present year)

a5: Education and training investment per employee

a6: Research and development investment to production value

a7: Salaries and wages to production value

a8: Cost of raw material to production value

a9: Value of resalable defective products to production value

a10: Value of finished good inventory to production value

a11: Value of in-process inventory to production value

a12: Value of raw material inventory to production value 
According to an international study by Ernest and Young and American Quality Foundation, the two most important management and organizational indicators are return on investment and value added per employee [65]. Return on investment reflects the financial attractiveness of an organization. Value added per employee presents the overall human productivity aspects of an organization. The randomly selected management and organization indicators are shown in Table 6. The third indicator is defined as production value per employee and reflects the workforce productivity of the production process. Production growth (indicator number 4) represents the percent production increase or decrease from previous year. The fifth and sixth indicators reflect training and research and development conditions in production systems, respectively. The seventh and eight indicators show the proportion of wages and salaries and cost of raw material to production value, respectively.

The structure and modeling approach of this study may be easily used for other manufacturing organizations with several sites. Principal component analysis (PCA) is used to rank and analyze the data. Numerical taxonomy and clustering are used to validate and verify PCA results. Consequently, PCA identifies the weak and strong points and introduces productivity and improving factors concerning management and organization conditions in each sector. As another approach, that has been developed in this paper, after clustering the data (to prepare k class), OLR has been used to check fitness of the model. Clustering and OLR has been used iteratively in the loop and finally proper model has been prepared .Finally, these two approaches have been compared. Fig. 1 presents the steps required to accomplish the integrated framework of this study.

Next section presents one illustration of the integrated framework for the analysis of two-digit ISIC sectors.

\subsection{Test problem}

The two-digit ISIC sectors are selected according to the format of International Standard for Industrial Classification (ISIC). The two-digit ISICs for all manufacturing products are listed as follows [69-72]: 


\begin{tabular}{ll}
\hline ISIC & Industry type \\
\hline 15 & Food and beverages \\
16 & Tobacco products \\
17 & Textiles \\
18 & Wearing apparel, fur \\
19 & Leather, leather products \\
20 & Wood products (excluding fumiture) \\
21 & Paper and paper products \\
22 & Printing and publishing \\
23 & Coke, refined petroleum products, nuclear fuel \\
24 & Chemicals and chemical products \\
25 & Rubber and plastics products \\
26 & Non-metallic mineral products \\
27 & Basic metals \\
28 & Fabricated metal products \\
29 & Machinery and equipment \\
30 & Office, accounting and computing machinery \\
31 & Electrical machinery and apparatus \\
32 & Radio, television and communication equipment \\
33 & Medical, precision and optical instruments \\
34 & Motor vehicles, trailers, semi-trailers \\
35 & Other transport equipment \\
36 & Furniture, manufacturing \\
37 & Recycling \\
\hline
\end{tabular}

Identify sectors to be studied ranked and analyzed assessment

Determine selected indicators for design an integrated database
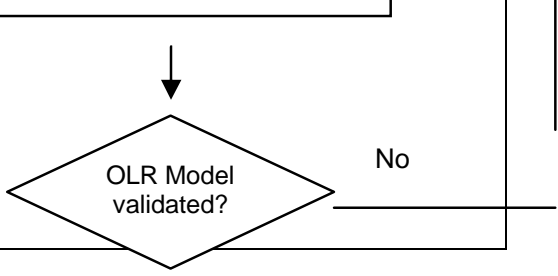


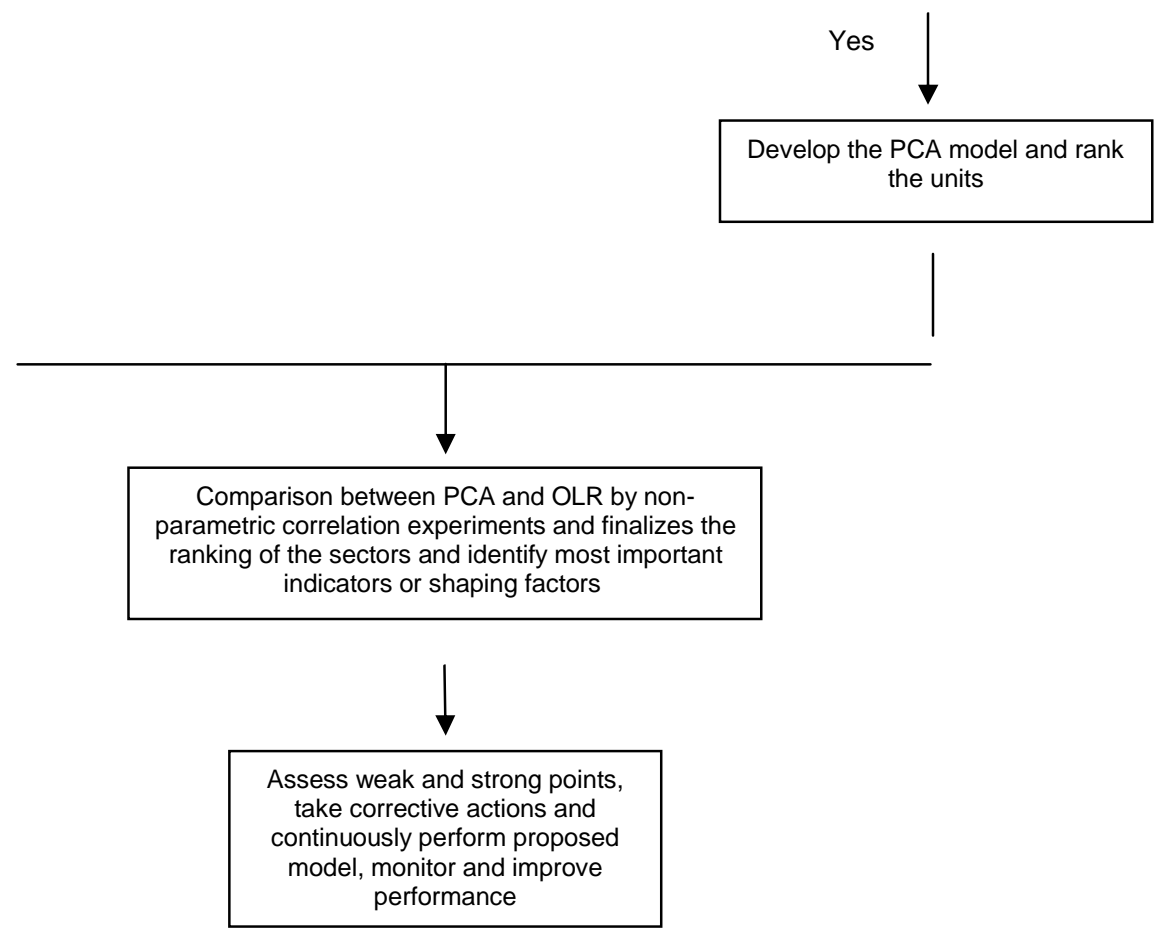

Fig. 1. The integrated approach for assessment of manufacturing systems based on management performance.

\subsection{PCA approach}

Step 1: Normalize the index vectors. The 12 indicators must be normalized and have same order to be used in PCA. The indicators $\mathrm{a}_{1}-\mathrm{a}_{6}$ have positive orders. Furthermore, indicators $\mathrm{a}_{7}-\mathrm{a}_{12}$ have negative orders and must be adjusted with the positive order indicators. To alleviate this problem, indicators $\mathrm{a}_{7}-\mathrm{a}_{12}$ are subtracted from 1 and all the 12 indicators from now on are referred to as $\mathrm{xj}$ for $\mathrm{j}=1 \ldots 12$.

Step 2: Standardize the indexes $\mathrm{x}_{1}-\mathrm{x}_{12}$. The indexes are standardized and are shown in Table 7 . They are standardized through predefined mean and standard deviation for each index. 
Step 3: Evaluate the correlation matrix. This matrix shows the values of linear correlation between indexes $\mathrm{x}_{1}$ and $\mathrm{x}_{12}$. Table 8 presents the correlation matrix.

Step 4: Eigenvalues, eigenvectors and proportion of the sample variance are calculated for all the 12 principal components (new variables). The eigenvalues and proportion of the sample variance for all the 12 principal components are presented in Table 9. It is noted that the first seven principal components $\mathrm{y}_{1}-\mathrm{y}_{7}$ account for about $95 \%$ of the sample variance. The coefficients of all principal components are shown in Table 10. The principal components are identified with PC1PC12. It should be noted that the coefficients are retrieved from the eigenvectors for the respective principal components.

Step 5: The principal components and aggregated weights are computed. The values of principal components and consequently their aggregated weights and principal components are presented in Table 11.

Table 7

Standardized matrix for the two-digit sectors

\begin{tabular}{|c|c|c|c|c|c|c|c|c|c|c|c|c|}
\hline Sector & $\hat{x}_{1}$ & $\hat{x}_{2}$ & $\hat{x}_{3}$ & $\hat{x}_{4}$ & $x_{5}$ & $x_{6}$ & $x_{7}$ & $\hat{x}_{8}$ & $\hat{x}_{9}$ & $\hat{x}_{10}$ & $\hat{x}_{11}$ & $\hat{x}_{12}$ \\
\hline 15 & -0.50 & -0.21 & 0.04 & -0.21 & -0.61 & -0.25 & 0.90 & -1.08 & -0.23 & 0.88 & 0.80 & 1.67 \\
\hline 16 & 1.68 & 0.24 & -0.13 & -0.07 & -0.88 & -1.21 & -0.26 & 1.90 & 1.38 & 0.95 & 1.01 & -0.32 \\
\hline 17 & -0.84 & -0.58 & -0.70 & -0.92 & -0.89 & -0.94 & -1.06 & -0.69 & -2.57 & -0.61 & -0.38 & 0.13 \\
\hline 18 & -0.64 & -0.65 & -0.87 & 0.64 & -1.09 & -1.29 & -1.11 & -0.94 & 0.57 & -0.66 & 0.80 & 0.80 \\
\hline 19 & -0.90 & -0.58 & -0.68 & -0.34 & -0.34 & -1.20 & -1.18 & -0.70 & 0.43 & -1.94 & 0.00 & 0.57 \\
\hline 20 & -0.21 & -0.43 & -0.61 & -0.09 & -0.69 & 0.53 & -0.98 & 0.69 & -1.37 & 0.83 & 0.39 & 1.23 \\
\hline 21 & -0.81 & -0.37 & -0.11 & -0.57 & -0.71 & -0.74 & 0.43 & -0.92 & -1.09 & 0.75 & 0.87 & -0.98 \\
\hline 22 & 0.90 & -0.15 & -0.61 & -0.18 & -0.58 & -0.05 & -1.67 & 0.90 & -0.26 & -2.65 & 0.55 & 0.16 \\
\hline 23 & 3.60 & 4.21 & 3.64 & 3.90 & -0.54 & -1.30 & 1.69 & 2.01 & 1.33 & 1.72 & 0.96 & 1.70 \\
\hline 24 & 0.61 & 0.62 & 0.73 & -0.92 & 1.15 & 0.74 & 0.90 & 0.75 & 0.26 & -0.07 & 0.82 & -0.19 \\
\hline 25 & -0.20 & -0.23 & -0.18 & 0.13 & 2.51 & -0.10 & 0.54 & -0.20 & -0.09 & 0.03 & 0.75 & 0.16 \\
\hline 26 & 0.21 & -0.37 & -0.62 & 0.08 & -0.41 & 0.74 & -0.91 & 1.76 & -0.25 & 0.52 & 0.31 & 0.48 \\
\hline 27 & -0.06 & 0.46 & 0.83 & -1.45 & 2.36 & -0.19 & 0.67 & 0.46 & 0.07 & -0.64 & -0.12 & 0.49 \\
\hline 28 & -0.19 & -0.33 & -0.50 & -0.56 & 0.92 & 0.60 & -0.68 & 0.18 & -1.19 & -0.60 & -1.26 & -0.98 \\
\hline 29 & -0.31 & -0.24 & -0.21 & -0.12 & 0.11 & 0.51 & 0.13 & -0.31 & -0.17 & -0.11 & -0.97 & -0.98 \\
\hline 30 & -0.13 & -0.10 & 0.11 & 0.16 & -0.45 & 2.45 & 1.52 & -1.11 & 1.30 & 0.23 & 0.54 & 0.89 \\
\hline 31 & -0.17 & -0.24 & -0.25 & 0.08 & 0.63 & 0.20 & 0.23 & -0.06 & -0.96 & -0.32 & 0.09 & -0.66 \\
\hline 32 & -0.45 & -0.06 & 0.39 & 0.24 & 0.14 & -0.19 & 1.11 & -0.97 & 1.25 & 0.97 & 0.02 & 0.33 \\
\hline 33 & -0.22 & -0.42 & -0.57 & -0.52 & -0.28 & 2.09 & -0.55 & 0.25 & 0.59 & -0.34 & -0.39 & -0.86 \\
\hline 34 & -0.57 & 0.33 & 1.45 & 0.33 & 0.49 & 0.47 & 1.46 & -1.31 & 0.94 & 0.73 & 0.13 & -0.97 \\
\hline 35 & -0.29 & -0.32 & -0.46 & -0.13 & 0.10 & -0.68 & -0.61 & -0.40 & -0.07 & 0.75 & -2.51 & -2.49 \\
\hline 36 & -0.51 & -0.56 & -0.70 & 0.51 & -0.98 & -0.21 & -0.57 & -0.20 & 0.14 & -0.43 & -2.41 & -0.19 \\
\hline
\end{tabular}




\section{Table 8}

Correlation matrix for the two-digit ISIC sectors

\begin{tabular}{|c|c|c|c|c|c|c|c|c|c|c|c|c|}
\hline Index & $\hat{x}_{1}$ & $\hat{x}_{2}$ & $x_{3}$ & $x_{4}$ & $\hat{x}_{5}$ & $\hat{x}_{6}$ & $\hat{x}_{7}$ & से & $x 9$ & $\hat{x}_{10}$ & $\hat{x}_{11}$ & $\hat{x}_{12}$ \\
\hline$\hat{x}_{1}$ & 1.00 & 0.86 & 0.69 & 0.68 & -0.06 & -0.18 & 0.26 & 0.79 & 0.42 & 0.30 & 0.34 & 0.29 \\
\hline$\hat{x}_{2}$ & 0.86 & 1.00 & 0.94 & 0.76 & 0.07 & -0.21 & 0.55 & 0.50 & 0.41 & 0.43 & 0.30 & 0.34 \\
\hline$\hat{x}_{3}$ & 0.69 & 0.94 & 1.00 & 0.65 & 0.20 & -0.12 & 0.76 & 0.27 & 0.46 & 0.51 & 0.31 & 0.27 \\
\hline$\hat{x}_{4}$ & 0.68 & 0.76 & 0.65 & 1.00 & -0.29 & -0.26 & 0.33 & 0.29 & 0.45 & 0.43 & 0.17 & 0.36 \\
\hline$x_{5}$ & -0.06 & 0.07 & 0.20 & -0.29 & 1.00 & 0.19 & 0.35 & 0.00 & 0.00 & -0.07 & -0.02 & -0.19 \\
\hline$\hat{x}_{6}$ & -0.18 & -0.21 & -0.12 & -0.26 & 0.19 & 1.00 & 0.19 & -0.07 & 0.07 & -0.01 & -0.07 & -0.11 \\
\hline$x_{7}$ & 0.26 & 0.55 & 0.76 & 0.33 & 0.35 & 0.19 & 1.00 & -0.16 & 0.48 & 0.61 & 0.30 & 0.16 \\
\hline$x 8$ & 0.79 & 0.50 & 0.27 & 0.29 & 0.00 & -0.07 & -0.16 & 1.00 & 0.11 & 0.11 & 0.20 & 0.17 \\
\hline$\hat{x}_{9}$ & 0.42 & 0.41 & 0.46 & 0.45 & 0.00 & 0.07 & 0.48 & 0.11 & 1.00 & 0.25 & 0.21 & 0.16 \\
\hline$\hat{x}_{10}$ & 0.30 & 0.43 & 0.51 & 0.43 & -0.07 & -0.01 & 0.61 & 0.11 & 0.25 & 1.00 & 0.15 & 0.07 \\
\hline$\hat{x}_{11}$ & 0.34 & 0.30 & 0.31 & 0.17 & -0.02 & -0.07 & 0.30 & 0.20 & 0.21 & 0.15 & 1.00 & 0.60 \\
\hline$\hat{x}_{12}$ & 0.29 & 0.34 & 0.27 & 0.36 & -0.19 & -0.11 & 0.16 & 0.17 & 0.16 & 0.07 & 0.60 & 1.00 \\
\hline
\end{tabular}

Table 9

Eigenvalues for the two-digit ISIC sectors

\begin{tabular}{rlll}
\hline Principal component & Eigenvalues $\left(\lambda_{j}\right)$ & Weight $\left(w_{j}\right)$ & Cumulative weights \\
\hline 1 & 4.796 & 39.971 & 39.971 \\
2 & 1.866 & 15.554 & 55.524 \\
3 & 1.313 & 10.945 & 66.469 \\
4 & 1.207 & 10.061 & 76.530 \\
5 & 0.922 & 7.687 & 84.217 \\
6 & 0.743 & 6.189 & 90.406 \\
7 & 0.532 & 4.437 & 94.843 \\
8 & 0.325 & 2.709 & 97.552 \\
9 & 0.198 & 1.648 & 99.200 \\
10 & 0.062 & 0.517 & 99.717 \\
11 & 0.027 & 0.227 & 99.944 \\
\hline
\end{tabular}

\section{Table 10}

Coefficients of principal components for the two-digit sectors

\begin{tabular}{|c|c|c|c|c|c|c|c|c|c|c|c|c|}
\hline & $l_{1_{p}}$ & $l_{2 p}$ & $l_{3 p}$ & $l_{4 p}$ & $l_{S p}$ & $I_{6 p}$ & $h_{p}$ & $l_{8_{p}}$ & $l_{g_{p}}$ & $l_{10 p}$ & $l_{11 p}$ & $l_{12 p}$ \\
\hline$\hat{x}_{1}$ & 0.390 & 0.238 & 0.249 & -0.174 & 0.110 & -0.007 & 0.057 & -0.141 & -0.049 & -0.550 & 0.479 & -0.358 \\
\hline$\hat{x}_{2}$ & 0.431 & 0.030 & 0.164 & -0.022 & -0.133 & 0.031 & -0.236 & -0.189 & -0.156 & 0.176 & 0.281 & 0.736 \\
\hline$x_{3}$ & 0.413 & -0.184 & 0.080 & 0.015 & -0.196 & 0.048 & -0.190 & -0.245 & -0.268 & 0.516 & -0.128 & -0.545 \\
\hline$\hat{x}_{4}$ & 0.362 & 0.161 & 0.034 & 0.337 & 0.084 & 0.125 & -0.321 & 0.060 & 0.737 & -0.036 & -0.229 & -0.042 \\
\hline$x_{s}$ & 0.003 & -0.439 & 0.240 & -0.522 & -0.403 & 0.141 & -0.010 & 0.379 & 0.356 & 0.025 & 0.154 & -0.026 \\
\hline $\bar{x}_{6}$ & -0.076 & -0.369 & -0.022 & -0.314 & 0.725 & -0.212 & -0.361 & -0.155 & 0.108 & 0.109 & 0.103 & -0.003 \\
\hline$\hat{x}_{7}$ & 0.291 & -0.528 & -0.141 & 0.055 & -0.079 & -0.055 & -0.013 & -0.093 & -0.194 & -0.567 & -0.472 & 0.119 \\
\hline$\hat{x}_{8}$ & 0.219 & 0.370 & 0.373 & -0.416 & 0.191 & -0.240 & 0.191 & 0.221 & -0.091 & 0.095 & -0.545 & 0.090 \\
\hline$\hat{x}_{9}$ & 0.260 & -0.169 & -0.053 & 0.091 & 0.428 & 0.649 & 0.442 & 0.246 & -0.091 & 0.139 & 0.051 & 0.051 \\
\hline$\hat{x}_{10}$ & 0.258 & -0.234 & 0.003 & 0.363 & 0.050 & -0.649 & 0.329 & 0.359 & 0.060 & 0.146 & 0.246 & -0.014 \\
\hline$\hat{x}_{11}$ & 0.212 & 0.079 & -0.567 & -0.366 & -0.091 & -0.115 & 0.423 & -0.411 & 0.329 & 0.117 & 0.003 & 0.048 \\
\hline$\hat{x}_{12}$ & 0.206 & 0.222 & -0.601 & -0.187 & -0.013 & -0.005 & -0.390 & 0.545 & -0.232 & -0.038 & 0.069 & -0.055 \\
\hline Sum & 2.969 & -0.823 & -0.241 & -1.140 & 0.673 & -0.289 & -0.079 & 0.576 & 0.509 & 0.132 & 0.012 & 0.001 \\
\hline
\end{tabular}

Table 11 
The values and scores of principal components for two-digit sectors

\begin{tabular}{|c|c|c|c|c|c|c|c|c|c|c|c|c|c|}
\hline Sector & $y_{1}$ & $y_{2}$ & $y_{3}$ & $y_{4}$ & $y_{5}$ & $y_{6}$ & $y_{7}$ & $y_{8}$ & $y_{9}$ & $y_{10}$ & $y_{11}$ & $y_{12}$ & $z_{i}$ \\
\hline 15.00 & 0.38 & -0.41 & -2.27 & 0.61 & -0.41 & -0.67 & -0.16 & 0.41 & -0.47 & -0.26 & 0.11 & -0.04 & 0.42 \\
\hline 16.00 & 1.86 & 1.65 & 0.56 & -0.12 & 0.58 & -0.16 & 2.37 & 0.13 & -0.36 & -0.31 & 0.02 & -0.06 & 0.38 \\
\hline 17.00 & -2.47 & 1.38 & -0.43 & 0.49 & -1.42 & -1.10 & -0.81 & -0.53 & -0.47 & -0.05 & 0.10 & -0.02 & -1.23 \\
\hline 18.00 & -0.78 & 1.59 & -1.70 & 1.00 & -0.22 & 1.13 & 0.45 & 0.16 & 0.60 & 0.18 & 0.13 & 0.04 & -0.56 \\
\hline 19.00 & -1.69 & 1.30 & -0.91 & 0.05 & -0.62 & 1.89 & -0.03 & 0.11 & -0.17 & 0.27 & -0.08 & 0.11 & -0.95 \\
\hline 20.00 & -0.53 & 1.25 & -0.84 & -0.34 & 0.42 & -1.85 & -0.46 & 0.63 & 0.13 & 0.32 & 0.14 & -0.07 & -0.09 \\
\hline 21.00 & -0.86 & -0.40 & -0.69 & 1.01 & -1.03 & -1.11 & 0.85 & -1.11 & 0.03 & 0.01 & -0.17 & 0.12 & -0.38 \\
\hline 22.00 & -0.92 & 2.52 & 0.17 & -1.59 & 0.43 & 1.22 & -0.34 & -0.97 & 0.05 & -0.18 & 0.06 & -0.15 & -0.67 \\
\hline 23.00 & 8.50 & 1.33 & 0.79 & 0.67 & -0.48 & 0.02 & -1.00 & -0.20 & 0.12 & 0.06 & 0.05 & 0.06 & 3.04 \\
\hline 24.00 & 1.03 & -1.10 & 0.33 & -1.78 & -0.05 & -0.16 & 0.41 & -0.43 & -0.47 & -0.02 & -0.02 & 0.09 & 0.69 \\
\hline 25.00 & 0.10 & -1.33 & -0.16 & -1.39 & -1.22 & 0.23 & 0.22 & 0.76 & 1.21 & -0.23 & 0.08 & 0.00 & 0.33 \\
\hline 26.00 & 0.00 & 1.26 & 0.16 & -0.85 & 1.19 & -1.16 & 0.28 & 0.66 & 0.26 & 0.31 & -0.31 & 0.01 & 0.04 \\
\hline 27.00 & 0.24 & -1.30 & 0.49 & -2.08 & -1.40 & 0.57 & -0.10 & 0.70 & -0.91 & 0.19 & -0.02 & 0.01 & 0.32 \\
\hline 28.00 & -1.76 & -0.24 & 1.57 & -0.62 & -0.19 & -0.34 & -0.72 & 0.01 & 0.18 & -0.06 & 0.16 & -0.03 & -0.73 \\
\hline 29.00 & -0.90 & -0.72 & 0.89 & 0.41 & 0.31 & 0.02 & -0.27 & -0.20 & 0.04 & -0.14 & -0.09 & 0.04 & -0.36 \\
\hline 30.00 & 0.72 & -1.98 & -1.73 & -0.08 & 2.13 & 0.25 & -0.63 & -0.24 & -0.11 & -0.36 & 0.12 & 0.03 & 0.96 \\
\hline 31.00 & -0.65 & -0.39 & 0.39 & -0.41 & -0.49 & -0.38 & -0.26 & -0.44 & 0.63 & -0.32 & -0.27 & 0.02 & -0.21 \\
\hline 32.00 & 0.82 & -1.44 & -0.84 & 1.01 & 0.01 & 0.46 & 0.45 & 0.59 & -0.12 & -0.01 & 0.00 & -0.03 & 0.51 \\
\hline 33.00 & -1.15 & -0.55 & 0.58 & -0.55 & 2.10 & 0.04 & -0.02 & -0.38 & 0.05 & 0.35 & 0.16 & 0.12 & -0.23 \\
\hline 34.00 & 1.00 & -2.52 & -0.09 & 0.93 & -0.15 & 0.45 & 0.16 & -0.72 & 0.12 & 0.51 & -0.13 & -0.22 & 0.65 \\
\hline 35.00 & -1.57 & -0.56 & 2.74 & 1.95 & -0.20 & 0.01 & 0.48 & 0.24 & 0.01 & 0.01 & 0.31 & 0.02 & -1.07 \\
\hline 36.00 & -1.36 & 0.65 & 0.99 & 1.67 & 0.71 & 0.65 & -0.90 & 0.82 & -0.35 & -0.26 & -0.33 & -0.02 & -0.85 \\
\hline
\end{tabular}

\subsection{Clustering-OLR approach}

Step 1: Using K-means approach, we obtain 7 classes in Table 12.

Step 2: For Ordinal Logistic Regression, we enter cluster column of table 12 as response and $\mathrm{x}_{1}-$ $\mathrm{x}_{12}$ as model. Table 13 presents the results. According to $\mathrm{p}$-values and calculated measures in this table, we conclude that the model fits the data adequately. Of course, as we mentioned before, we reach to this result after checking other values for $\mathrm{k}$ (number of clusters).

Step 3: For each cluster of table 12, run the PCA model separately and according to calculated scores, rank the sectors of each cluster. This new ranking has been shown in Table 14. 


\section{Table 12}

Clustering for obtain 7 classes

\begin{tabular}{|c|c|c|c|c|c|c|c|c|c|c|c|c|c|}
\hline $\begin{array}{c}\text { sector } \\
\mathrm{s}\end{array}$ & X1 & $\mathrm{X} 2$ & X3 & $\mathrm{X} 4$ & $\times 5$ & X6 & X7 & X8 & X9 & X10 & X11 & $\mathrm{X} 12$ & $\begin{array}{l}\text { Cluster } \\
\text { (k-meas) }\end{array}$ \\
\hline 15 & -0.5 & $\begin{array}{c}- \\
0.2 \\
1\end{array}$ & $\begin{array}{c}0.0 \\
4\end{array}$ & $\begin{array}{c}- \\
0.2 \\
1\end{array}$ & $\begin{array}{c}- \\
0.6 \\
1\end{array}$ & $\begin{array}{c}- \\
0.2 \\
5\end{array}$ & 0.9 & $\begin{array}{c}- \\
1.0\end{array}$ & $\begin{array}{c}- \\
0.2 \\
3\end{array}$ & $\begin{array}{c}0.8 \\
8\end{array}$ & 0.8 & $\begin{array}{c}1.6 \\
7\end{array}$ & 1 \\
\hline 16 & $\begin{array}{c}1.6 \\
8\end{array}$ & $\begin{array}{c}0.2 \\
4\end{array}$ & $\begin{array}{c}- \\
0.1 \\
3\end{array}$ & $\begin{array}{c}- \\
0.0 \\
7\end{array}$ & $\begin{array}{c}- \\
0.8 \\
8\end{array}$ & $\begin{array}{c}- \\
1.2 \\
1\end{array}$ & $\begin{array}{c}- \\
0.2 \\
6\end{array}$ & 1.9 & $\begin{array}{c}1.3 \\
8\end{array}$ & $\begin{array}{c}0.9 \\
5\end{array}$ & $\begin{array}{c}1.0 \\
1\end{array}$ & $\begin{array}{c}- \\
0.3 \\
2\end{array}$ & 2 \\
\hline 17 & $\begin{array}{c}- \\
0.8 \\
4\end{array}$ & $\begin{array}{c}- \\
0.5 \\
8\end{array}$ & -0.7 & $\begin{array}{c}- \\
0.9 \\
2\end{array}$ & $\begin{array}{c}0.8 \\
9\end{array}$ & $\begin{array}{c}- \\
0.9 \\
4\end{array}$ & $\begin{array}{c}- \\
1.0 \\
6\end{array}$ & $\begin{array}{c}- \\
0.6 \\
9\end{array}$ & $\begin{array}{c}- \\
2.5 \\
7\end{array}$ & $\begin{array}{c}- \\
0.6 \\
1\end{array}$ & $\begin{array}{c}- \\
0.3 \\
8\end{array}$ & $\begin{array}{c}0.1 \\
3\end{array}$ & 3 \\
\hline 18 & $\begin{array}{c}- \\
0.6 \\
4\end{array}$ & $\begin{array}{c}- \\
0.6 \\
5\end{array}$ & $\begin{array}{c}- \\
0.8 \\
7\end{array}$ & $\begin{array}{c}0.6 \\
4\end{array}$ & $\begin{array}{c}- \\
1.0 \\
9\end{array}$ & $\begin{array}{c}- \\
1.2 \\
9\end{array}$ & $\begin{array}{c}- \\
1.1 \\
1\end{array}$ & $\begin{array}{c}- \\
0.9 \\
4\end{array}$ & $\begin{array}{c}0.5 \\
7\end{array}$ & $\begin{array}{c}- \\
0.6 \\
6\end{array}$ & 0.8 & 0.8 & 4 \\
\hline 19 & -0.9 & $\begin{array}{c}- \\
0.5 \\
8\end{array}$ & $\begin{array}{c}- \\
0.6 \\
8\end{array}$ & $\begin{array}{c}- \\
0.3 \\
4\end{array}$ & $\begin{array}{c}0.3 \\
4\end{array}$ & -1.2 & $\begin{array}{c}- \\
1.1 \\
8\end{array}$ & -0.7 & $\begin{array}{c}0.4 \\
3\end{array}$ & $\begin{array}{c}- \\
1.9 \\
4\end{array}$ & 0 & $\begin{array}{c}0.5 \\
7\end{array}$ & 5 \\
\hline 20 & $\begin{array}{c}- \\
0.2 \\
1\end{array}$ & $\begin{array}{c}- \\
0.4 \\
3\end{array}$ & $\begin{array}{c}- \\
0.6 \\
1\end{array}$ & $\begin{array}{c}- \\
0.0 \\
9\end{array}$ & $\begin{array}{c}- \\
0.6 \\
9\end{array}$ & $\begin{array}{c}0.5 \\
3\end{array}$ & $\begin{array}{c}- \\
0.9 \\
8\end{array}$ & $\begin{array}{c}0.6 \\
9\end{array}$ & $\begin{array}{c}1.3 \\
7\end{array}$ & $\begin{array}{c}0.8 \\
3\end{array}$ & $\begin{array}{c}0.3 \\
9\end{array}$ & $\begin{array}{c}1.2 \\
3\end{array}$ & 6 \\
\hline 21 & $\begin{array}{c}- \\
0.8 \\
1\end{array}$ & $\begin{array}{c}- \\
0.3 \\
7\end{array}$ & $\begin{array}{c}- \\
0.1 \\
1\end{array}$ & $\begin{array}{c}- \\
0.5 \\
7\end{array}$ & $\begin{array}{c}- \\
0.7 \\
1\end{array}$ & $\begin{array}{c}- \\
0.7 \\
4\end{array}$ & $\begin{array}{c}0.4 \\
3\end{array}$ & $\begin{array}{c}- \\
0.9 \\
2\end{array}$ & $\begin{array}{c}- \\
1.0 \\
9\end{array}$ & $\begin{array}{c}0.7 \\
5\end{array}$ & $\begin{array}{c}0.8 \\
7\end{array}$ & $\begin{array}{c}- \\
0.9 \\
8\end{array}$ & 7 \\
\hline 22 & 0.9 & $\begin{array}{c}- \\
0.1 \\
5\end{array}$ & $\begin{array}{c}- \\
0.6 \\
1\end{array}$ & $\begin{array}{c}- \\
0.1\end{array}$ & $\begin{array}{c}- \\
0.5 \\
8\end{array}$ & $\begin{array}{c}- \\
0.0 \\
5\end{array}$ & $\begin{array}{c}- \\
1.6 \\
7\end{array}$ & 0.9 & $\begin{array}{c}- \\
0.2 \\
6\end{array}$ & $\begin{array}{c}- \\
2.6 \\
5\end{array}$ & $\begin{array}{c}0.5 \\
5\end{array}$ & $\begin{array}{c}0.1 \\
6\end{array}$ & 5 \\
\hline 23 & 3.6 & $\begin{array}{c}4.2 \\
1\end{array}$ & $\begin{array}{c}3.6 \\
4\end{array}$ & 3.9 & $\begin{array}{c}0.5 \\
4\end{array}$ & -1.3 & $\begin{array}{c}1.6 \\
9\end{array}$ & $\begin{array}{c}2.0 \\
1\end{array}$ & $\begin{array}{c}1.3 \\
3\end{array}$ & $\begin{array}{c}1.7 \\
2\end{array}$ & $\begin{array}{c}0.9 \\
6\end{array}$ & 1.7 & 2 \\
\hline
\end{tabular}


$\begin{array}{cccccccccccccc} & 0.6 & 0.6 & 0.7 & - & 1.1 & 0.7 & & 0.7 & 0.2 & - & 0.8 & - & \\ & 1 & 2 & 3 & 0.9 & 5 & 4 & 0.9 & 5 & 6 & 0.0 & 2 & 0.1 & 1\end{array}$

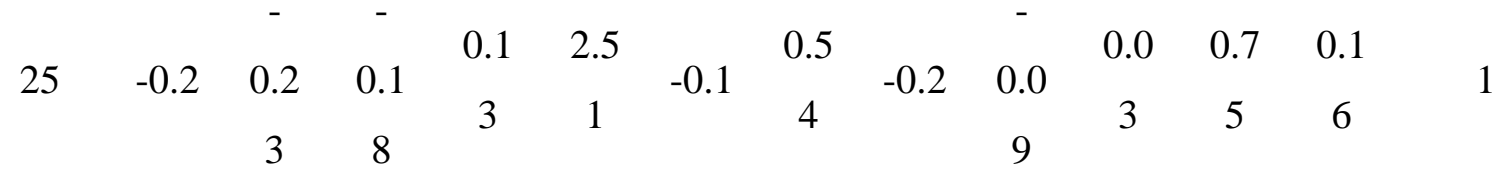

$\begin{array}{cccccccccccccc} & 0.2 & - & - & 0.0 & - & 0.7 & - & 1.7 & - & 0.5 & 0.3 & 0.4 & \\ & 1 & 0.3 & 0.6 & 8 & 0.4 & 4 & 0.9 & 6 & 0.2 & 2 & 1 & 8 & \end{array}$

$\begin{array}{cccccccccccccr} & - & 0.4 & 0.8 & - & 2.3 & - & 0.6 & 0.4 & 0.0 & - & - & 0.4 & \\ & 0.0 & 6 & 3 & 1.4 & 6 & 0.1 & 7 & 6 & 7 & 0.6 & 0.1 & 9 & 1 \\ & 6 & & & 5 & & 9 & & & & 4 & 2 & & \end{array}$

$\begin{array}{cccccccccccccc} & - & - & & - & & & - & & - & & - & - & \\ 28 & 0.1 & 0.3 & -0.5 & 0.5 & 0.9 & 0.6 & 0.6 & 0.1 & 1.1 & -0.6 & 1.2 & 0.9 & 3 \\ & 9 & 3 & & 6 & 2 & & 8 & 8 & 9 & & 6 & 8 & \end{array}$

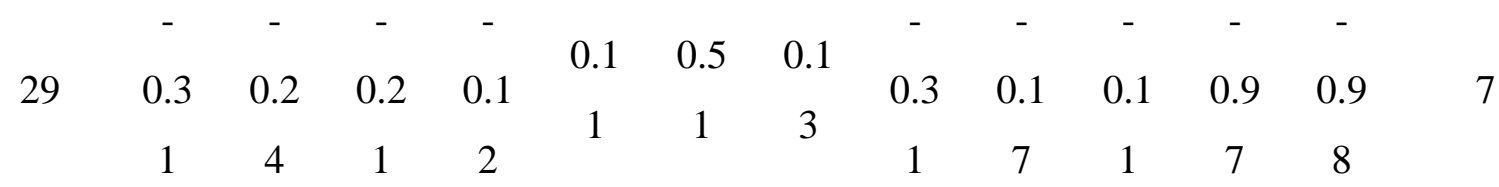

$\begin{array}{cccccccccccccr}30 & 0.1 & -0.1 & 0.1 & 0.1 & - & 2.4 & 1.5 & - & & 0.2 & 0.5 & 0.8 & 1 \\ & 3 & & 1 & 6 & 0.4 & 5 & 2 & 1.1 & 1.3 & 3 & 4 & 9 & \end{array}$

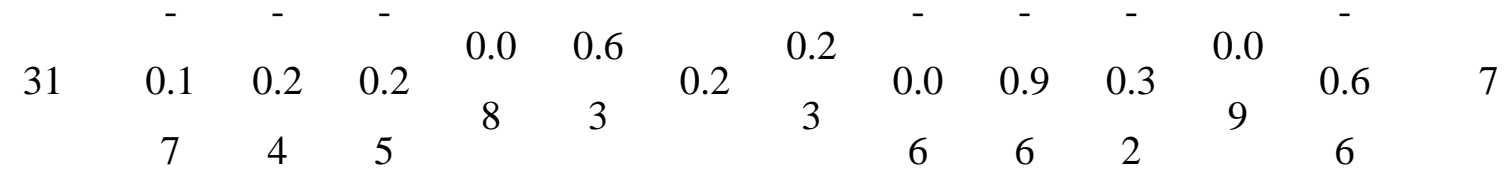

$\begin{array}{cccccccccccccr} & - & - & 0.3 & 0.2 & 0.1 & - & 1.1 & - & 1.2 & 0.9 & 0.0 & 0.3 & \\ & 0.4 & 0.0 & 9 & 4 & 4 & 0.1 & 1 & 0.9 & 5 & 7 & 2 & 3 & 1 \\ 5 & 6 & & & & 9 & & 7 & & & & & \end{array}$

$\begin{array}{cccccccccccccc} & - & - & - & - & - & & - & & & - & - & - & \\ 33 & 0.2 & 0.4 & 0.5 & 0.5 & 0.2 & 2.0 & 0.5 & 0.2 & 0.5 & 0.3 & 0.3 & 0.8 & 6 \\ & 2 & 2 & 7 & 2 & 8 & 9 & 5 & 5 & 9 & 4 & 9 & 6 & \end{array}$

$\begin{array}{llllllllllllll}34 & - & 0.3 & 1.4 & 0.3 & 0.4 & 0.4 & 1.4 & - & 0.9 & 0.7 & 0.1 & - & 1\end{array}$ 


\begin{tabular}{ccccccccccccccc} 
& 0.5 & 3 & 5 & 3 & 9 & 7 & 6 & 1.3 & 4 & 3 & 3 & 0.9 & \\
& 7 & & & & & & & 1 & & & & 7 & \\
& - & - & - & - & & - & - & & - & & - & - & \\
35 & 0.2 & 0.3 & 0.4 & 0.1 & 0.1 & 0.6 & 0.6 & -0.4 & 0.0 & 0.7 & 2.5 & 2.4 & 7 \\
& 9 & 2 & 6 & 3 & & 8 & 1 & & 7 & 5 & 1 & 9 & \\
& - & - & & & - & - & - & & & - & - & - & \\
36 & 0.5 & 0.5 & -0.7 & 0.5 & 0.9 & 0.2 & 0.5 & -0.2 & 0.1 & 0.4 & 2.4 & 0.1 & 5 \\
& 1 & 6 & & 1 & 8 & 1 & 7 & & 4 & 3 & 1 & 9 & \\
\hline
\end{tabular}

\section{Table 13}

Ordinal Logistic Regression Table.

\section{$95 \% \mathrm{CI}$}

Predictor Coef SE Coef Z P Odds Ratio Lower Upper

$\begin{array}{lllll}\text { Const(1) } & -2.61652 & 1.42834 & -1.83 & 0.067\end{array}$

Const(2) $\quad 0.447419 \quad 1.15896 \quad 0.390 .699$

Const(3) $\quad 2.32012 \quad 1.25682 \quad 1.85 \quad 0.065$

Const(4) $\quad 2.81976 \quad 1.28006 \quad 2.20 \quad 0.028$

Const(5) $\quad 4.26646 \quad 1.38918 \quad 3.07 \quad 0.002$

Const(6) $\quad 6.19146 \quad 1.70913 \quad 3.62 \quad 0.000$

$\begin{array}{llllllll}\mathrm{X} 1 & 11.5483 & 4.15927 & 2.78 & 0.005 & 103604.29 & 29.85 & 3.59598 \mathrm{E}+08\end{array}$

$\begin{array}{llllllll}\mathrm{X} 2 & -12.5087 & 5.47539 & -2.28 & 0.022 & 0.00 & 0.00 & 0.17\end{array}$

$\begin{array}{llllllll}\mathrm{X} 3 & 10.0817 & 4.62449 & 2.18 & 0.029 & 23901.40 & 2.77 & 2.06477 \mathrm{E}+08\end{array}$

$\begin{array}{llllllll}\mathrm{X} 4 & -5.38133 & 1.96371 & -2.74 & 0.006 & 0.00 & 0.00 & 0.22\end{array}$

$\begin{array}{llllllll}X 5 & 2.93848 & 1.14386 & 2.57 & 0.010 & 18.89 & 2.01 & 177.76\end{array}$

$\begin{array}{llllllll}\text { X6 } & -0.0693975 & 0.771407 & -0.09 & 0.928 & 0.93 & 0.21 & 4.23\end{array}$

$\begin{array}{llllllll}X 7 & -2.35537 & 2.11983 & -1.11 & 0.267 & 0.09 & 0.00 & 6.05\end{array}$

$\begin{array}{llllllll}\text { X8 } & -6.19274 & 2.56159 & -2.42 & 0.016 & 0.00 & 0.00 & 0.31\end{array}$

$\begin{array}{llllllll}\text { X9 } & 1.36348 & 0.769580 & 1.77 & 0.076 & 3.91 & 0.87 & 17.67\end{array}$

$\begin{array}{llllllll}\text { X10 } & 2.24580 & 1.08489 & 2.07 & 0.038 & 9.45 & 1.13 & 79.22\end{array}$

$\begin{array}{llllllll}\mathrm{X} 11 & -2.78457 & 1.09355 & -2.55 & 0.011 & 0.06 & 0.01 & 0.53\end{array}$ 
$\begin{array}{llllllll}\text { X12 } & 6.64949 & 1.96938 & 3.38 & 0.001 & 772.39 & 16.27 & 36661.25\end{array}$

Log-Likelihood $=-20.004$

Test that all slopes are zero: $\mathrm{G}=38.936, \mathrm{DF}=12, \mathrm{P}-\mathrm{V}$ alue $=0.000$

Goodness-of-Fit Tests

Method Chi-Square DF $\mathrm{P}$

Pearson $\quad 155.0321140 .006$

Deviance $\quad 40.0081141 .000$

Measures of Association:

(Between the Response Variable and Predicted Probabilities)

Pairs Number Percent Summary Measures

$\begin{array}{lllll}\text { Concordant } & 183 & 93.4 & \text { Somers' D } & 0.87\end{array}$

Discordant $\quad 13 \quad 6.6$ Goodman-Kruskal Gamma 0.87

$\begin{array}{lllll}\text { Ties } & 0 & 0.0 & \text { Kendall's Tau-a } & 0.74\end{array}$

Total $196 \quad 100.0$

\section{Table 14}

Ranking in the clusters.

\begin{tabular}{|c|c|c|c|}
\hline \multirow{2}{*}{ cluster } & \multirow{2}{*}{ Sector } & $\begin{array}{r}\text { ranking in the cluster } \\
\text { new ranking based } \\
\text { on PCA in the } \\
\text { cluster }\end{array}$ & $\begin{array}{r}\text { rank for score based on } \\
\text { first PCA }\end{array}$ \\
\hline \multirow{2}{*}{1} & 15 & 7 & 7 \\
\cline { 2 - 4 } & 24 & 2 & 1 \\
\hline
\end{tabular}




\begin{tabular}{|c|c|c|c|}
\hline & 25 & 3 & 4 \\
\hline & 27 & 1 & 3 \\
\hline & 30 & 5 & 6 \\
\hline & 32 & 6 & 5 \\
\hline & 34 & 4 & 2 \\
\hline \multirow{2}{*}{2} & 16 & 1 & 2 \\
\hline & 23 & 2 & 1 \\
\hline \multirow{2}{*}{3} & 17 & 1 & 2 \\
\hline & 28 & 2 & 1 \\
\hline 4 & 18 & 1 & 1 \\
\hline \multirow{3}{*}{5} & 19 & 2 & 3 \\
\hline & 22 & 1 & 1 \\
\hline & 36 & 3 & 2 \\
\hline \multirow{3}{*}{6} & 20 & 1 & 2 \\
\hline & 26 & 2 & 1 \\
\hline & 33 & 3 & 3 \\
\hline \multirow{4}{*}{7} & 21 & 1 & 3 \\
\hline & 29 & 3 & 2 \\
\hline & 31 & 2 & 1 \\
\hline & 35 & 4 & 4 \\
\hline
\end{tabular}

\section{Comparison between two approach}

In this regard, the ranking of the two approaches should be analyzed by Spearman correlation experiments. Result has been shown in table 15. According to this table. Only for cluster "1", we have a good result.

\section{Table 15}

Spearman correlation experiments

Correlation experiment
(Spearman)


1

Pearson correlation $=0.786$

$\mathrm{P}-$ Value $=0.036$

2

Pearson correlation $=-1.00$

3

Pearson correlation $=-1.00$

5

Pearson correlation $=0.500$

P-Value $=0.667$

6

Pearson correlation $=0.500$

7

$\mathrm{P}$-Value $=0.667$

Pearson correlation $=0.400$

$\mathrm{P}-$ Value $=0.600$

\section{CONCLUSION}

In summary, a unique integrated framework is presented to assess managerial and organizational factors in manufacturing systems. Managers may use this type of modeling approach to assess the performance of various production sites with respect to the management and organizational indicators. In turn, the selected sites would be ranked based on an integrated scientific approach, which reveals the standing of each site with respect to a series of standard management indicators. This would enable managers of manufacturing systems to continuously monitor and improve managerial and organizational performance. In addition, they may want to compare management performance of a particular site or all sites with that of similar organizations or competitors. This would bring about further insights and knowledge of their standings in respect to competitors.

The integrated approach of this study may be used to assess the importance of each of the selected indicators

for industrial units of interest. Managers may utilize the integrated approach to continuously monitor and analyze units' performance in respect to management performance and identify most important indicators or shaping factors. Moreover, managers and policymakers may use the prescribed approach to continuously rank and analyze sectors and identify weak and strong management factors. 
In summary, this paper presents a unique standard methodology for assessment and ranking of manufacturing

sectors based on integrated management and organization productivity. The structure and approach of this paper could be easily applied to other production systems. The results of such studies would help policy makers and top managers to have better understanding of their sectors with respect to managerial and organizational conditions. Also, designers and engineers could identify weak and strong points concerning management and organization. The framework presented in this paper may be used by top managers to compare the management performance of various units within an industrial organization. This may be accomplished by defining the target units (say n DMUs) and ranking them with respect to the 12 indicators discussed in this paper. Therefore, they will have standard scientific results about the standings of all units with respect to management and organization productivity. Second, the most important management indicators will be identified which will help managers improve weak points in respect to management conditions. Finally, the modeling approach may be extended to include external units (competitors) to identify standings and weak and strong management factors in the big picture.

\section{REFERENCES}

[1] M.A. Azadeh, Creating highly reliable manufacturing systems: an integrated approach, International Journal of Reliability Quality and Safety Engineering 7 (3) (2000).

[2] M.A. Azadeh, Creating high reliable manufacturing systems: an integrated approach, in: Proceedings of the Fourth International Conference on Reliability, Maintainability and Safety (ICRMS'99), Shanghai, China 1999.

[3] J.A. Tompkins, W. Bozer, E.H. Frazelle, J.M.A. Tanchoco, J. Trevino, Facilities Planning, John Wiley \& Sons, New York, 1996.

[4] K.D. Barber, R.H. Hollier, The use of numerical analysis to classify companies according to production control complexity, International Journal of Production Research 24 (1) (1986).

[5] R. Bolden, P. Waterson, P. Warr, C. Clegg, A new taxonomy of modern manufacturing practices, Internationl Journal of Operations and Production Management 17 (11) (1997).

[6] P. Jonsson, An empirical taxonomy of advanced manufacturing technology, International Journal of Operations and Production Management 20 (12) (2000). 
[7] McCarthy, Manufacturing classification: lessons from organizational systematic and biological taxonomy, Integrated Manufacturing Systems 6 (6) (1995).

[8] T.G. Schmitt, T. Klastorin, A. Shtub, Production classification system: concepts, models and strategies, International Journal of Production Research 23 (3) (1985).

[9] T.J. Harris, C.T. Seppala, L.D. Desborough, A review of performance monitoring and assessment techniques for univariate and multivariate control systems, Journal of Process Control 9 (1999).

[10] A. Shaw, A Guide to Performance Measurement and Non-Financial Indicators, The Foundation for Performance Mea urement, Surrey, United Kingdom, 1999.

[11] D. Hitchens, J.E. Birnie, K. Wagner, A matched plant comparison of productivity in East and West Germany: transition to the market economy, Omega 24 (3) (1996).

[12] K. Hitomi, Analysis of Manufacturing Efficiency: Efficiency Analysis of Japan's Manufacturing, Center for Manufacturing Systems Engineering, Kyoto, Japan, 2003.

[13] H.K. Hong, S.H. Ha, C.K. Shin, S.C. Park, S.H. Kim, Evaluating the efficiency of integration projects using DEA and machine learning, Expert Systems with Applications 16 (1999).

[14] C. Madu, Reliability and quality interface, International Journal of Quality \& Reliability Management 16 (7) (1999).

[15] V.N. Bhat, A multivariate analysis of airline flight delays, International Journal of Quality \& Reliability 12 (2) (1995).

[16] T. Garcia, I. Grande, A model for valuation of farmland in Spain: the case of multivariate analysis, Journal of Property Investment and Finance 21 (2) (2003).

[17] T.K. Madsen, Successful export marketing management: some empirical evidence, International Marketing Review 6 (4) (1989).

[18] N. Meade, Strategic positioning in UK car market, European Journal of Marketing 21 (5) (1987).

[19] A. Mehrez, H. Hu, F. Offodile, Multivariate economic analysis of robot performance repeatability and accuracy, Journal of Manufacturing Systems 15 (4) (1996).

[20] L.H. Chen, C. Kao, S. Kuo, T.Y. Wang, Y.C. Jang, Productivity diagnosis via fuzzy clustering and classification: an application to machinery industry, Omega 24 (3) (1996). 
[21] T. Guimaraes, N. Matensson, J. Stahre, M. Igbaria, Empirically testing the impact of manufacturing complexity on performance, International Journal of Operations and Production Management 19 (12) (1999).

[22] M. Terziovski, Achieving performance excellence through integrated strategy of radical innovation and continuous improvement, Measuring Business Excellence 6 (2) (2002).

[23] S. Kumar, Application of multivariate analysis techniques in understanding industrial process: a pulp mill example, Pulping and Bleaching Analysis and Control Group, University of Washington, USA, 1998.

[24] F. Karakaya, C. Canel, Underlying dimensions of business location, International Management \& Data Systems (2000) 321-329.

[25] M. Matsudaira, Q. Hong, Features \& characteristic values of fabric compress ional curves, International Journal of Clothing Science and Technology 6 (2/3) (1994) 37-43.

[26] M.A. Azadeh, S. Jalal, Identifying the economic importance of industrial sectors by multivariate analysis, Journal of the Faculty of Engineering, University of Tehran, Iran (2001) $120-135$.

[27] M.A. Azadeh, A multivariate model for assessment of industrial sectors based on machinery indicators, in: 30th International Conference on Computers \& Industrial Engineering, 29 June-2 July 2002, Tinos Island, Greece, 2002.

[28] M.A. Azadeh, V. Ebrahimipour, G.R. Ataei, A total machine productivity model for assessment and improvement of electrical manufacturing systems, in: 32nd International Conference in Computers and Industrial Engineering, Limerick, Ireland, August, 2003.

[29] M.A. Azadeh, V. Ebrahimipour, A multivariate approach for assessment and improvement of machinery and equipment manufacturers based on machine performance, in: The 6th International Conference on Engineering Design and Automation, Maui, Hawaii, 2002.

[30] M.A. Azadeh, V. Ebrahimipour, An integrated approach for assessment of manufacturing sectors based on machine performance: the cases of automotive and food and beverages industries, in: Proceedings of the Manufacturing Complexity Conference, Cambridge University, England, 2002.

[31] V. Pradova, C.S. Boucon, B. de Jong, D.L. Walczak, Three-way principal component analysis applied to food analysis: an example, Analytica Chimica Acta 462 (2002).

[32] S. Sharma, Applied Multivariate Techniques, John Wiley \& Sons, New York, 1996. 
[33] J. Zhu, Data envelopment analysis vs. principal component analysis: an illustrative study of economic performance of Chinese cities, European Journal of Operation Research 111 (1998) $50-61$.

[34] M. Enlin, Use of principal component analysis in selecting plants for fluoride, Chinese Journal of Ecology 14 (3) (1995).

[35] F. Rossi, A.A. Thomas, Analysis of the beverage data using cluster analysis, rotated principal components analysis and LOESS curves, Food Quality and Preference 12 (2001).

[36] F.K. Wang, T.C.T. Du, Using principal component analysis in process performance for multivariate data, Omega 28 (2000) 185-194.

[37] S. Gamesalingam, K. Kumar, Detection of financial distress via multivariate statistical analysis, Managerial Finance 27 (4) (2001).

[38] W. Wang, Z. Xu, J.W. Lu, Three improved neural network for air quality forecasting, Engineering Computations 20 (2) (2003).

[39] E.B. Martin, A.J. Morris, C. Kiparissides, Manufacturing performance enhancement through multivariate statistical process control, Annual Reviews in Control 23 (1999).

[40] R. Minhas, E. Jacobs, Benefit segmentation by factor analysis: an improved method of targeting customers for financial services, International Journal of Bank Marketing (1996) 3-13.

[41] E. Nagai, T.C.E. Cheng, Identifying potential barriers to total quality management using principal component analysis and correspondence analysis, International Journal of Quality and Reliability Management 14 (4) (1997) 391-408.

[42] R. Agarwala, On the approximability of numerical taxonomy (fitting distances by tree metrics), SIAM Journal on Computing 28 (3) (1999) 1073-1085.

[43] J. Cohen, M. Farach, Numerical taxonomy on data: experimental results, Department of Computer Science, Rutgers University, New Jersey, USA, 1997.

[44] P. Gaibraith, C. Haines, Conceptual misunderstandings of beginning undergraduates, International Journal of Mathematical Education in Science \& Technology 31 (2000) 651-660.

[45] A. Ricketts, H. Taylor, Who's where in North America? Bioscience 49 (1999) 369-375.

[46] S. Thomas, Dendroram \& Celestial tree: numerical taxonomy and variants of the iroquoian creation myth, The Canadian Journal of Native Students (1987) 195-221.

[47] A. Buja, D. Cook, Interactive high-dimensional data visualization, Journal of Computational and Graphical Statistics 5 (1) (1996) 78 -99. 
[48] M. Chavent, A monothetic clustering method, Pattern Recognition Letters 19 (1998) 989996.

[49] Q. He, A Review of Clustering Algorithms as Applied in IR, Graduate School of Library and Information Science, University of Illinois at Urban-Champaign, USA, 1999.

[50] C.R. Hulten, Total factor productivity: a short biography, in: C.R. Hulten, E.R. Dean, M.J. Harper (Eds.), New Developments in Productivity Analysis, University of Chicago Press for the National Bureau of Economic Research, Chicago, 2001.

[51] C.S. Sarrico, S.M. Hogan, R.G. Dyson, A.D. Athanassopoulos, Data envelopment analysis and university selection, Journal of the Operational Research Society 48 (1997) 1163-1177.

[52] Y. Tat, J. Raymond, Levels of satisfaction among Asian and Western travelers, International Journal of Quality \& Reliability Management 17 (2) (2000) 116-132.

[53] T.H. Davenport, Process Innovation, Reengineering Wok through Information Technology, Harvard Business School Press, 1993.

[54] R.S. Kaplan, Balanced Score Card: Translating Strategy into Action, Harvard Business S.P., 1996.

[55] A.J. Rucci, S.P. Kirn, R.T. Quinn, The employee-customer profit chain at sears, Harvard Business Review (September-October) (1998).

[56] S. Shingo, A Revolution in Manufacturing, Productivity Press, 1985.

[57] R. Simons, Performance Measurement and Control Systems for Implementing Strategy, Prentice Hall, New York, 2000.

[58] A.C. Hax, N.S. Majluf, The Strategy Approach and Process: A Pragmatic Approach, Prentice Hall, New York, 1996.

[59] R.S. Kaplan, D.P. Norton, Putting balanced score card to work, Harvard Business Review (January-February) (1993).

[60] J.F. Proud, Master Scheduling: A Practical Guide to Competitive Manufacturing, Wiley and Sons, New York, 1999.

[61] A.M. Schneiderman, Why balanced score card failed, Journal of Strategic Performance Measurement (1999) (Special edition).

[62] M. Schneiderman, Measurement: the bridge between the hard and soft sides, Journal of Strategic Performance Measurement (April-May) (1998). 
[63] D.L. Waller, Operation Management: A Supply Chain Approach, International Business Press, 1999.

[64] M. Zain Mohammed, T. Rickards, Assessing and comparing the innovativeness and creative climate of firms, Scandinavian Journal of Management 96 (3-6) (1996) 109-121.

[65] O. Port, G. Smith, Quality: small and midsize companies seize the challenge - not a moment too soon, Business Week 30 (November) (1992).

[66] M.F. Turker, E.S. Turker, The socio-economic analysis of fuelwood consumption with the principal components analysis in Turkey, Bioresearch Technology 60 (2) (1997).

[67] U.N. International Standard Industries Classification of All Economic Activities, Series M No. 4/Rev. 3, 20, 1993.

[68] UNIDO Industrial Development: Global Report, 1997.

[69] World Bank World Development Report, 1995.

[70] World Bank World Development Indicators, 1998.

[71] UNIDO International Year Book of Industrial Statistics, 1999.

[72] US Department of Labor Multifactor Productivity Measures for Three-digit SIC Manufacturing Industries, US Department of Labor, Bureau of Labor Statistics, Report 948, December, 2000.

[73] M.A. Azadeh, V. Ebrahimipour, An integrated approach for assessment and ranking of manufacturing systems based on machine performance, International Journal of Industrial Engineering 11 (4) (2004) 349-363.

How to cite this article:

Massoudi H R, Jafari-eskandari M, Aliahmadi A. Reduction in the balanced scorecard performance measurement systems in manufacturing organizations by pca. J. Fundam. Appl. Sci., 2016, 9(1S), 291-316. 